\title{
Ankle ligament injuries
}

\author{
Per A F H Renström, Lars Konradsen
}

Injuries to the ligaments of the ankle are often called "low ankle sprains". If the tibiofibular ligament or the syndesmosis is injured it is called a "high ankle sprain".

Inversion sprains with injury to the lateral ligaments of the ankle/foot complex are by far the most common. They occur with an estimated frequency of one injury per 10000 people per day, amounting to about 27000 injuries each day in the United States. ${ }^{12}$ Although many injuries are treated outside medical establishments, $7-10 \%$ of those who are visiting the emergency departments of the hospitals in Scandinavia have sprained ankles. ${ }^{3}$

Ankle injuries are the most common injuries in sports and recreational activity. ${ }^{4-12}$ For this reason, probably, these injuries tend to occur primarily to young people. ${ }^{13}$ The sprained ankle also remains the most common injury regardless of whether the sport is primarily an upper or a lower extremity sport. Garrick ${ }^{7}$ noted that injuries to the ankle accounted for $53 \%$ of injuries occurring during basketball and for $31 \%$ of those occurring during soccer. Reviewing 41 soccer teams, Ekstrand and Tropp ${ }^{14}$ found ankle sprains to account for 17 to $21 \%$ of the injuries. The "high ankle sprain" usually occurs as the result of an eversion injury in combination with fractures or lesions to the deltoid ligament. Isolated syndesmosis injuries occur in 3\% of the cases. This article will deal mainly with the lateral ligament complex.

\section{Ankle biomechanics}

The passive stability of the ankle is the responsibility of the ligaments and the bony constraints of the ankle joint, while the active stability depends on muscular support. The talus has no muscular insertion. Active motion depends on the long foot muscles inserting into other tarsal or metatarsal bones. Dorsiflexion and inversion are effected by the extensor hallucis longus and the anterior tibial muscles. Dorsiflexion and eversion are guided by the peroneus tertius muscles and extensor digitorum longus and brevis muscles. Plantar flexion and eversion are effected by the peroneus longus and brevis muscles. Plantar flexion and inversion are regulated by the flexor hallucis longus, the flexor digitorum, and the posterior tibial muscles. ${ }^{15}$

The ligaments of the ankle can be divided into the lateral group, the medial group, and the ligaments of the syndesmosis.

The lateral ankle ligament complex is traditionally considered to consist of the anterior talofibular (ATFL), the calcaneofibular (CFL), and the posterior talofibular (PTFL) ligaments. However, in inversion the subtalar ligaments, especially the cervical ligament, the interosseous ligament, and the ligaments spanning the calcaneocuboid and the talonavicular joints, also have to be considered.

Many studies have been done on talotibial ligaments to gain insight into how they function together to stabilise the joint. Of the talotibial ligaments, the ATFL is a thin $6-10$ mm wide, $20 \mathrm{~mm}$ long, and $2 \mathrm{~mm}$ thick ${ }^{16}$ weak ligament, being essentially a thickening of the anterior ankle joint capsule. It passes from the distal anterior origin of the lateral malleolus to the talus in front of the proximal part of the lateral articular surface. In neutral position its direction is parallel to a long axis of the foot and in full plantar flexion it is more parallel with the tibia (fig 1). The CFL is a $20-25 \mathrm{~mm}$ long rounded ligament with a diameter of $6-8$ $\mathrm{mm} .{ }^{16}$ It is an extra-articular ligament closely associated with the peroneal tendon sheath. It runs obliquely downwards and backwards to be attached to the lateral surface of the calcaneus. There is a great variety in its direction and in its attachment sites. ${ }^{15} \mathrm{~A}$ rupture to this ligament will also cause a rupture of the tendon sheath, and occasionally also damage the peroneal tendons.

The ATFL acts as a primary restraint against plantar flexion, as well as internal rotation of the foot. ${ }^{17}$ In strain studies Renström et $a l^{18}$ found that the strain of the ATFL significantly increases with increasing plantar flexion. In the neutral position the ligament is relaxed. ${ }^{19}$

The CFL does not have an independent role in talotibial joint stability, but acts instead as a guide for the axis of subtalar motion. ${ }^{17}$ In dorsiflexion the ligament has increased strain. ${ }^{18}$ In a normal standing position the ligaments remain relaxed.

The lateral talocalcaneal (LTCL) extends from the talus to the calcaneus and blends its fibres with CFL and ATFL fibres. The exact incidence of injury to this ligament is not known. Transecting the subtalar ligaments results in very limited increase in motion when measured in degrees, but as they have very limited motion in the first place the increase after rupture is about $40 \% .{ }^{20}$ The incidence of rupture here is also unknown.

The PTFL connects the posterolateral tubercle of the talus to the medial aspect of the lateral malleolus. The PTFL has an average diameter of $6 \mathrm{~mm}$. In plantar flexion and in the neutral position the ligament is relaxed, whereas in dorsiflexion the ligament is tensed. ${ }^{15}$ The clinical significance of PTFL injuries is somewhat unclear, but it is not commonly damaged. The ATFL, CFL, and PTFL ligaments function as a unit for the talotibial complex, though one may resist a specific motion depending upon foot position. ${ }^{21}$ 

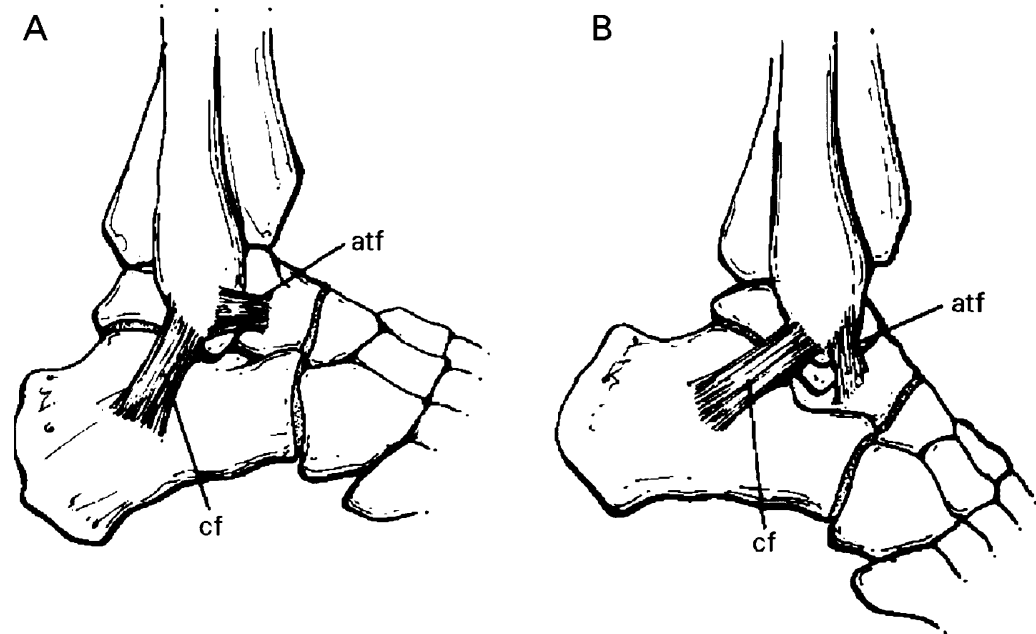

Figure 1 (A) Anterior talofibular (atf) ligament runs parallel to the axis of the foot when the foot is in neutral position. $C f=$ calcaneofibular ligament. (B) When the foot is in plantar flexion, the anterior talofibular ligament assumes a course parallel to the axis of the tibia and fibula.
Frequency of lesions caused by inversion sprains

Owing to the ATFL's vulnerable position in plantar flexion, it is the most commonly ruptured ligament in a lateral ankle sprain. ${ }^{1323}$ 29-34 In 1964 Broström $^{16}$ surgically explored 105 sprained ankles and found an isolated ATFL tear present in about two thirds of the cases. The second most common injury was a combined rupture of the ATFL and CFL, occurring in about 20 to $25 \%$ of the cases. ${ }^{131634}$ Other isolated ligamentous injuries are relatively uncommon. ${ }^{1316}$ The PTFL, for instance, is a very strong ligament and is rarely injured except in severe ankle trauma. ${ }^{29} 35$

Ligamentous lesions after acute inversion sprains cannot, however, be seen in such a limited scope. Thus Broström ${ }^{13}$ noted that in a group of 321 patients with acute ankle sprains, $19 \%$ had signs of injury to the bifurcate or the dorsal calcaneocuboid ligaments, or both. Gerner-Smidt ${ }^{36}$ in a combined study of children and adults found that $22 \%$ of the patients sustained lesions to the talonavicular or the calcaneocuboid ligaments, or both, and Hølmer et $a b^{37}$ found clinical evidence of isolated calcaneocuboid/calcaneocervical or talonavicular ligament lesions in $15-25 \%$ of inversion injuries. Meyer et $a l^{88}$ evaluated 40 patients with acute ankle sprains (it is not mentioned, but they must have been considered clinically grade II to III) with subtalar arthrograms. ${ }^{39}$ Apart from lesions to the lateral tibiotalar joint ligaments, 17 patients (43\%) showed contrast leaks into the sinus tarsi, suggesting interosseous ligament rupture. Some of these patients were operated on and the cervical ligament was often found to be severed too.

Chondral or osteochondral lesions of the talar dome have been noted by Taga et $a l^{40}$ in $89 \%$ and by van $\operatorname{Dijk}^{15}$ in $66 \%$ of acute inversion injuries. In $1991 \mathrm{Grana}^{41}$ found chondral lesions in $80 \%$ and osteochondral lesions in $6.5 \%$ of acute ankle injuries. Lesions to peroneal tendons ranging from total tendon rupture or insertion site fracture to longitudinal slits occur, and the tendon injuries are often overlooked. ${ }^{42}$ Injury to the superficial and deep peroneal nerves ranging from the rare condition of complete nerve palsy ${ }^{4344}$ to, what seems to be much more common, discrete conduction velocity changes have been noted. ${ }^{45}{ }^{46}$ In rarer cases fractures to the cuboid, the anterior process of the calcaneus, and the lateral process of the talus have been diagnosed after an inversion injury. ${ }^{47-49}$

ateral ligament injuries is a situation where the ankle goes into a combination of plantar flexion and inversion. The ATFL tears first followed by rupture of the anterolateral capsule. With further inversion, the CFL will be ruptured followed by variable injury to the PTFL and the anterior part of the deltoid ligaments. ${ }^{27}$

With weight bearing, the articular surface can provide $30 \%$ of stability in rotation, and $100 \%$ stability in inversion. ${ }^{26}$ This ability is a function not only of the axial load but also of the close packed position. ${ }^{28}$ Ankle destabilisation thus occurs during loading and unloading, but the joint is stable once it is fully loaded.

\section{Grading lateral ligament injury} classified in three groups based on severity. ${ }^{4} \mathrm{~A}$ grade I injury involves stretch of the ligament without macroscopic tearing, little swelling or tenderness, slight or no functional loss, and no mechanical instability of the joint. A grade II injury is a partial macroscopic tear of the ligament with moderate pain, swelling, and tenderness over the affected structures. Some
Clinically, sprains of the lateral ankle have been loss of motion and mild or moderate instability 
of the joint occurs. In a grade III injury, there is complete rupture of the ligament with severe swelling, haemorrhage, and tenderness. There is loss of ability to bear weight on the foot, limited function, and considerable abnormal motion and instability of the joint. An improved and validated classification of ankle sprains is needed. The terms mentioned above were validated by Lindenfeld ${ }^{50}$ and found to be quite subjective. Others prefer to classify lateral ligament injuries as single or double ligament tears. A single injury would imply lesions to only the ATFL, a double injury would affect both the ATFL and the CFL. The distinction in clinical terms is difficult here also.

\section{Diagnosis}

Diagnosing the extent of an acute lateral ligament injury is not considered very accurate because of pain, swelling, and muscle tenderness. ${ }^{15}$ In the first few days after injury local palpational pain is often diffuse, with no maximal point of tenderness. ${ }^{15152}$ The extent of swelling does not depend only on the magnitude of the ligamental injury but also on the initial treatment. Extensive swelling is a predictor of ligament rupture, but the positive predictive value has been found to be only $60-70 \% .^{53-55}$ The characteristic haematoma suggesting ligament rupture usually does not develop during the first few days, and joint range of motion is mainly determined by the severity of pain and does not differ between simple sprains and ligament rupture..$^{555}$ Furthermore, the interobserver variation of the acute examination concerning tenderness, swelling, discoloration, and the anterior drawer sign is considerable. ${ }^{56}$ The anterior drawer sign seems to be a good predictor of lateral ligament disruption. Broström ${ }^{30}$ found that the anterior drawer sign was positive in all of 239 patients with ligament rupture. His examination was, however, done with general or local anaesthesia. Without anaesthesia he could only elicit a positive drawer sign in two patients. Based on these results van $\mathrm{Dijk}^{57}$ suggests that the physical examination should be delayed four to five days after the initial injury. The specificity and sensitivity of delayed physical examination for the presence or absence of a rupture to the ATFL were found to be $84 \%$ and $96 \%$ respectively, and the delayed examination, done by observers of varying degrees of experience, gave information of ligament quality that equalled that of arthrography. After four to five days a combination of tenderness at the level of the anterior talofibular ligament, lateral haematoma discoloration, and a positive drawer sign indicated a ligament lesion in $95 \%$ of the cases. A negative drawer test and the absence of discoloration always indicated an intact ligament.

Radiographs to exclude fractures are suggested according to the Ottowa strategy for ankle injury. ${ }^{58}$ Plain radiographs are taken if there is bone tenderness at the tip or posterior aspect of the lateral malleolus, at the tip or posterior aspect of the medial malleolus, at the navicular tuberosity or at the base of the fifth metatarsal, or if the patient is unable to bear weight immediately after injury and at the initial examination. With these rules the authors could reduce the use of radiographs from $80 \%$ to $63 \%$ of the injuries.

\section{Treatment of lateral ligament lesions}

TREATMENT OF GRADE I AND II SPRAINS

In the presence of a grade I or grade II injury it is universally agreed that recovery is fast with non-operative management and the prognosis is good. ${ }^{4559}$ Jackson et $a T^{9}$ found that early mobilisation resulted in a disability of eight days for a grade I and 15 days for a grade II injury. Functional treatment including early motion and use of ankle support and early weight bearing is today the accepted treatment for grade I and II ankle sprains.

TREATMENT OF GRADE III SPRAINS

In the case of grade III lateral ligament lesions the treatment of choice-that is, whether to operate, to immobilise in a cast, or to allow early controlled mobilisation, is more controversial. The key consideration being the question of whether ligament healing with adequate tension can be achieved equally well with early controlled mobilisation as with direct visualisation and suturing.

If the ankle is kept from excess inversion or dorsal or plantar flexion the strain in the lateral ligaments remains low, ${ }^{18}$ allowing for adequate healing conditions without elongation within this range of guided motion. With the development of lower extremity magnetic resonance imaging scanning, studies have visualised that total ligament (grade III) ruptures do heal with ligamental continuity if there is early mobilisation. There is thus experimental evidence supporting ankle ligament healing in the presence of early mobilising treatment.

Clinically many uncontrolled, nonrandomised studies have shown mechanical stability and satisfactory subjective results after both operative and conservative treatment. Of the many papers available, only 12 could be considered prospective and randomised ${ }^{30} 5560-69$ when a comparison between operative and conservative treatments was performed by Kannus and Renström. ${ }^{35}$ Six of these considered the three treatment groups in question: operation, immobilising and early mobilising modalities, ${ }^{306263656669}$ and the results and conclusions based on these reports will be mentioned in the following. Duration of follow up ranged from six months to 3.8 years, which is considered adequate time to identify persistent disability. Results were evaluated using selected outcome parameters. Return to work or physical activity was reported in four of the studies that included three treatment modalities. $^{30616669}$ They concluded that return to work was two to four times faster after functional treatment than after operation or immobilisation in a cast. Return to pre-injury level of activity was found to be faster after conservative treatment than after operative treatment in four cases. ${ }^{61626669}$ The opposite was found in 
three studies ${ }^{305563}$ and no difference was found in the remaining five.

Pain, swelling, or stiffness with activity could be evaluated in four of the studies involving three treatment groups. $^{62636669}$ The studies failed to show any differences. In the three studies that included three therapy groups and included mobility of the ankle,$^{306699}$ mobility was found to be superior after functional treatment compared with the other two methods.

Better mechanical stability has been the primary argument for operation. Assessment of mechanical stability calls for an objective measurement with the evaluation of talar tilt and anterior drawer on stress radiographs. Based on five studies evaluating the three different treatments, ${ }^{6265666869}$ equal stability results were found.

Functional instability is not a well defined entity but designates repeated inversion injuries that are either unprovoked or the result of very little provocation. Functional instability seems to be a late disability in 15 to $60 \%$ of lateral ligament injuries depending on the definition applied. In the studies that reported on functional instability ${ }^{306266971}$ opinions diverged, but no one treatment seemed superior to the others in minimising the chances of late instability. The scientific basis for treating chronic functional instability is discussed later in this review.

The review of Kannus and Renström ${ }^{35}$ concludes that functional treatment is the treatment of choice when treating grade III acute lesions of the lateral ligaments. Recent comparative studies do not change this view. Konradsen $e t a l^{22}$ and Eiff $e t a l^{33}$ concluded that in first time lateral ankle sprains, although both immobilisation and early mobilisation prevent late residual problems and ankle instability, early mobilisation allows early return to work and, possibly, is more comfortable for patients. In a recent prospective study comparing surgery with functional treatment in ankle ligament tears Kaikkonen and coworkers ${ }^{74}$ found that early mobilisation gave better results than surgery plus mobilisation in treatment of complete tears of lateral ligaments of the ankle. Nine months after injury excellent to good scores were achieved in $87 \%$ of the functionally treated patients and $60 \%$ of the surgically treated patients respectively. In a metaanalytical article Schrier $^{75}$ found functional treatment was superior to immobilisation in casts, reducing both ankle instability and the cost of treatment.

Sommer and Schreiber ${ }^{76}$ considered the cost-benefit aspects by comparing immobilisation in a plaster cast followed by immobilisation with a brace, with early mobilisation using a brace only. Early functional therapy proved to be the treatment with the least direct costs. Leanderson and Wredmark ${ }^{77}$ in a study of 73 patients with grade II and III sprains treated with either early mobilisation or immobilisation found that the socioeconomic savings were potentially significant with ankle brace treatment. Nationally, the potential yearly savings in Sweden using this treatment were estimated to be eight million American dollars. The treatment of choice thus remains functional treatment.

If acute surgery is considered necessary the indications could according to Leach and Schepsis ${ }^{78}$ be (a) a history of momentary talocrural dislocation with complete ligamentous disruption, (b) a major clinical anterior drawer sign, (c) 10 degrees more tilt on the affected side with stress inversion testing, $(d)$ clinical or radiographic suspicion of tears in both the ATFL and CFL, and (e) osteochondral fracture. Most techniques described for repair of acute ligament injuries are similar to that of Broström. ${ }^{30}$ The results after acute surgery are in general very good with return to sport in 10 to 12 weeks. This must still be compared with the three to six weeks after functional treatment.

\section{Acute treatment protocol}

BIOLOGICAL BACKGROUND

In the post-injury phases of an acute severe ankle injury, an ideal treatment and rehabilitation programme should fulfil four requirements ${ }^{35}$ :

1 The RICE principle: rest, ice (cold), compression, and elevation aims to minimise haemorrhage, swelling, inflammation, cellular metabolism, and pain in order to offer the best possible conditions for the healing process. $^{7980}$

2 Protection of the injured ligaments during the first one to three weeks is required. In this phase of healing (the proliferation phase), protective ankle support is followed by undisturbed fibroblast invasion of the injured area, which leads to undisturbed proliferation and production of collagen fibres. Mobilisation too early in inversion leads to more prolonged type III collagen formation with weaker healing tissue than during optimal immobilisation. ${ }^{80-82}$ Protection is also needed to prevent secondary injuries and early distension and lengthening of the injured ligaments.

3 About three weeks after the injury the maturation phase of the collagen and the formation of final scar tissue begins. ${ }^{81-83} \mathrm{In}$ this phase the injured ligaments need controlled mobilisation, and perhaps even more importantly, the ankle itself must avoid the deleterious effects of immobilisation on joint cartilage, bone, muscles, tendons, and ligaments. ${ }^{8}{ }^{83-90}$ Controlled stretching of muscles and movement of the joint enhance the orientation of collagen fibres parallel with the stress lines (that is, the normal collagen fibres of the ligaments), and they can prevent the atrophy caused by immobilisation. ${ }^{80}$ Repeated exercises will also increase the mechanical and structural properties of the ligaments. ${ }^{91}$

4 About four to eight weeks after the injury the new collagen fibres begin to withstand almost normal stress, and the goal for rehabilitation is rapid recovery and full return to work and sports.

If treated according to the guidelines mentioned above, each component of the ankle is 
ready for a gradually increasing mobilisation and rehabilitation programme, keeping in mind that final maturation and remodelling of the injured ligaments takes a long time-from six to 12 months.

\section{Residual disability after inversion injury}

Inadequate rehabilitation is the primary cause of residual disability after ankle sprains. Many athletes return to sports before they are fully rehabilitated and therefore they are often subjected to reinjury or additional injury. Examination may show loss of range of motion, especially limited dorsiflexion, and atrophy of lower leg muscles.

Residual disability after ankle inversion injury can be divided into primarily instability problems and pain-giving entities.

\section{CHRONIC ANKLE INSTABILITY}

Chronic ankle instability can be subdivided into mechanical, functional, and subtalar instability and the sinus tarsi syndrome.

\section{Mechanical instability}

Mechanical instability is characterised by ankle mobility beyond the physiological range of motion, which is identified on the basis of a positive anterior drawer or talar tilt test, or both. ${ }^{92}$ The radiographic criteria for mechanical instability vary. Most authors agree, however, that mechanical instability is present when there is more than $10 \mathrm{~mm}$ of anterior translation on one side or the side-to-side difference is over $3 \mathrm{~mm}$ or the talar tilt is more than 9 degrees on one side, or the side-to-side difference is more than 3 degrees. $^{93}$ Pure mechanical instability of the ankle is seldom the sole independent reason for the development of late symptoms. Mann et al, showed that $81 \%$ of patients with radiographically documented instability experienced recurrent sprains. $^{94}$

\section{Functional instability}

Functional instability is the chronic disability after an ankle inversion injury that can be attributed to lateral ankle ligament deficiency and is characterised by "giving way" problems. Forty eight per cent of patients with an acute first time sprain have recurrent sprains and $26 \%$ report frequent sprains. ${ }^{94}$ The definition of the symptom is ambiguous and the pathogenesis is unclear. It does not seem to be dependent on the grade of the initial injury ${ }^{69}$ nor does it correlate with the degree of initial mechanical instability. ${ }^{6164}{ }^{69-95}$ No histological ligamentous changes except scarring have been found in chronic ankle disability. ${ }^{30}$

As anatomical studies showed the presence of mechanoreceptors in joint ligaments and capsule, and clinical studies showed decreased postural control in patients with functional instability, Freeman et al suggested that functional instability was due to motor incoordination secondary to a proprioceptive disorder. ${ }^{96}$ Postural control was later measured objectively using stabilometry by Tropp ${ }^{95}$ who, like Freeman, found increased postural sway in subjects with functionally unstable ankles. It is, how- ever, clear that functional instability is a complex syndrome where mechanical, proprioceptive, and muscular disabilities either alone or in combination are at fault. Known factors include mechanically insufficient ligaments, peroneal muscle weakness, ${ }^{95}$ subtalar instability, ${ }^{97}$ and proprioceptive deficit. ${ }^{9596}$

Although increased postural swaying has been used as a measure for a proprioceptive deficit, there is no direct causal connection between swaying with an increased amplitude when balancing on one foot and sustaining recurrent inversion injuries. Rather it seems reasonable to assume that a common and superior deficit is responsible for both disabilities. The nature of such a disability remains unclear. The latency of the peroneal muscles has been found to be significantly slower in functionally unstable ankles by some ${ }^{98-100}$ but not by others. ${ }^{101-103}$ An increased error in detecting ankle inversion movement or in matching ankle inversion angles has again been found by some ${ }^{104-106}$ but not by others. ${ }^{107}$ There is, however, evidence that $(a)$ a proprioceptive deficit may result after an acute ankle inversion injury, ${ }^{4670108}$ (b) proprioceptive defects measured in different ways are seen in subjects with functional instability, and (c) models exist that may explain how measurable kinaesthetic deficits may cause an increased frequency of ankle inversion injuries (Konradsen $e t$ al, unpublished data).

\section{Subtalar instability}

The incidence of subtalar sprains is unknown, but it is widely accepted that most subtalar ligamentous injuries occur in combination with injuries of the lateral ligaments of the ankle (fig 2). Subtalar instability is estimated to be present in about $10 \%$ of patients with lateral ankle instability. The symptoms of chronic subtalar instability include giving way episodes during activity and a feeling of instability when walking on uneven ground. These symptoms may coincide with chronic talocrural instability and therefore careful clinical examination is necessary. Localised tenderness on palpation over the subtalar joint is suggestive of a subtalar sprain. The diagnosis can be verified with subtalar arthrography ${ }^{38}$ or a subtalar stress view or stress tomography.

Functional treatment similar to the regimen used for lateral sprains is the treatment of choice. Surgery with non-anatomical procedures has been described. ${ }^{109110}$ Anatomical repairs, however, show equally good results. ${ }^{97111}$

\section{Sinus tarsi syndrome}

The sinus tarsi syndrome is often accompanied by a feeling of instability and giving way of the ankle. Seventy per cent of the patients will have experienced a severe inversion sprain. ${ }^{92}$ If the calcaneofibular ligament is torn the interosseous talocalcaneal ligament occupying the sinus will often also be sprained. This sprain will cause synovitis in the sinus tarsi with rather localised pain. The diagnosis can be made based on a complaint of pain and tenderness of the sinus tarsi combined with the giving way 


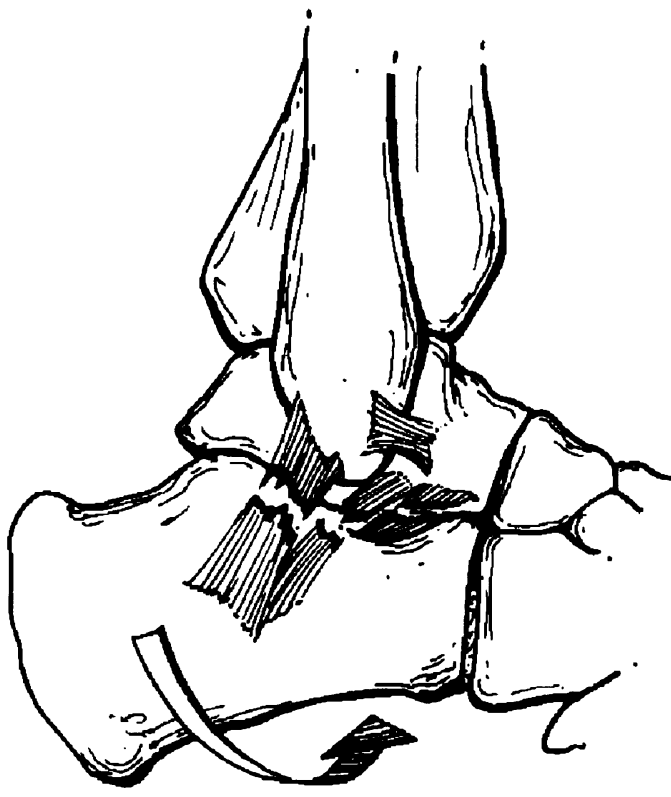

Figure 2 Forceful inversion of the hindfoot in neutral flexion. Tearing of the calcaneofibular, the cervical, and the interosseous ligaments. (From Meyer $\mathcal{F M}$, Garcia $\mathcal{F}$,

Hoffmeyer $P$, Fritchy $D$. The subtalar sprain. A roentgenographic study. Clin Orthop 1988;226:169-73.)

feeling. The pain and the giving way feeling can usually be relieved by local injections of anaesthetic and corticosteroids. Excision of tissue filling the sinus tarsi can give good results if conservative treatment fails.

\section{TREATMENT OF CHRONIC INSTABILITY \\ Rehabilitation}

With the uncertain pathogenesis of functional ankle instability the elements of treatment protocols will rest primarily on personal experiences and not so much on scientific data. Before deciding upon surgical treatment, a well planned rehabilitation programme based on peroneal muscle strengthening and coordination training should be carried out. Regaining muscle strength is primarily achieved by increasing neural activation through functionally oriented training and dynamometer training. ${ }^{12}$ In functional training the patient is required to activate his/her musculature in normally occurring activities. Dynamic stability, including proprioceptive information, motor control, and appropriate muscle force development, will be enforced by the training.

Treatment of the proprioceptive ankle deficit consists of a progressive series of coordination exercises to re-educate the ankle. Tropp ${ }^{95}$ found a significant improvement in balance during single limb stance in subjects with a functionally unstable ankle after six weeks of balance board exercises (fig 3). The same group reported a decrease in the frequency of inversion injuries and ankle giving way feelings when compared with an untrained control group with unstable ankles. Tropp ${ }^{95}$ also found that the subjects in question showed a change in their strategy of single limb stance, going from a broken chain strategy before training to the normal inverted pendulum strategy after completed training. So it may well be, as suggested by Glencross and Thornton, ${ }^{104}$ that

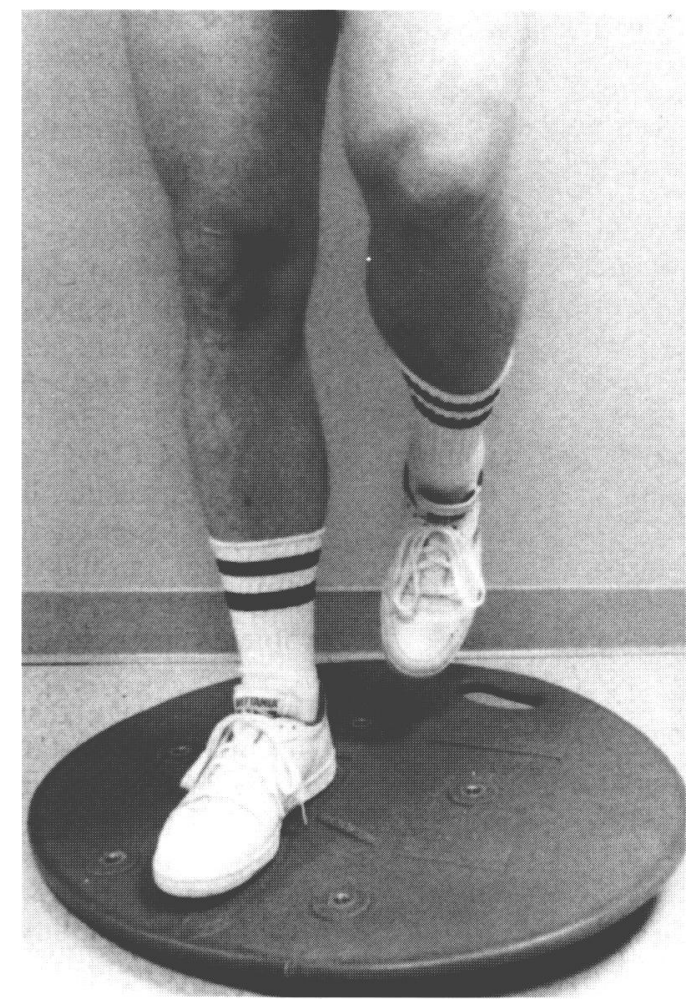

Figure 3 Tilt board training is an excellent way to return neuromuscular control to the injured ankle.

rehabilitation was as much a relearning programme as it was a physical recovery after injury. Often the injured subjects themselves have a clear feeling of a perception/ proprioception deficit in the ankle joint areathey cannot "feel" the ankle as they used to. When this feeling returns it seems to coincide with complete rehabilitation. Leanderson et $a l^{108}$ found that return of single limb balance to normal values coincided with a subjective feeling of full rehabilitation in dancers. It can, however, be argued that in this group balance during single limb stance was as much a specific functional test as an unspecific test for ankle proprioception.

In summary, training proprioceptive function through coordination exercises using unilateral balance boards, uniaxial and multiaxial teeter boards, and jumping ropes relies primarily on empirical data but produces very favourable results. Restitution of normal function relies on the individual's subjective feeling of return to normal sensation. Full effect of training is achieved within 10-12 weeks as evaluated by postural sway. ${ }^{95}$

About $50 \%$ of patients with functional instability will regain satisfactory functional stability after such a programme. ${ }^{113}$

\section{EXTERNAL SUPPORT}

When considering the mechanical effect of the different external support modalities it is important to remember that even though they do increase the resistance to inversion, the effect cannot be compared with that of active evertor muscles. Ashton-Miller et $a l^{144}$ found that active evertor muscles, acting isometrically on a 15 degrees inverted ankle, can provide more than three times the protection against 
further ankle inversion than tape or an orthosis worn inside a three-quarter-top shoe.

\section{Tape}

The primary purpose of taping is to provide increased stiffness to the ankle and a semirigid and sometimes rigid splinting around it. Studies have shown that taping the ankle prevents ankle injuries. Garrick et al found that the combination of taping prophylactically and the use of high top shoes in basketball reduced the frequency of ankle sprains. ${ }^{114 a}$ Lindenberger et $a l^{15}$ found that tape had a significant prophylactic effect in handball team players who were studied prospectively for two full seasons. Six top level teams participated in the first year. In three teams the players wore tape and in the other three teams the players did not. During the first season 13 ankle sprains occurred-all in the non-taped group. In the second season nine teams participated. Twenty one ankle sprains occurred and 20 of these were in the non-taped group.

Contrary to this, several studies have shown that tape loses as much as $50 \%$ of its supportive effect after only 10 minutes of active exercise $\mathrm{e}^{116-118}$ and offers virtually no support after one hour. ${ }^{119}$ The mechanism behind the effect of ankle taping thus remains unclear. However, tape does not only restrict extensive joint motion but also enhances proprioceptive feedback mechanism and shortens the recruitment time of the dynamic ankle stabilisers. ${ }^{120}$

Many athletes may have a skin reaction to tape and therefore skin protection may be used. There seems to be no difference in support between tape directly on the skin and tape with skin protections. Because of these skin problems, tape is used mostly by top athletes and not by recreational athletes.

\section{Braces}

The use of ankle orthoses has increased over the past decade. In contrast with tape the mechanical effect of a brace does not wear off with activity as shown by Shapiro et al. ${ }^{121}$

Not many clinical trials have been performed judging the effect of ankle bracing on the frequency of ankle inversion injuries. In a retrospective trial Rovere $e t$ al $^{122}$ found a reduction of sprains in football using a lace-on cloth brace. Tropp et $a l^{95}$ in a prospective study showed the effect of a semirigid ankle brace in reducing the frequency of injuries in soccer players, and in a prospective randomised study Sitler et $a l^{123}$ found that ankle stabilisers significantly reduced the frequency of ankle injuries but not their severity in a group of basketball players at West Point, New York. The resistance to an eversion moment seems to be the same for ankle braces as that for newly applied tape. ${ }^{114}$ Like tape, braces have been shown to have a proprioceptive enhancing effect. ${ }^{124}$

There have been discussions about the effect on performance of tape and braces. In sprinting a reduction in maximal speed has been found by most, ${ }^{125}$ but not by all. ${ }^{126}$ For vertical jumping most studies also show that a brace decreases ability. ${ }^{126-128}$ Opinions about bracing compared with taping vary, with some studies showing a smaller effect and others a larger detrimental effect of tape compared with braces. It must be noted that most of the studies were done on subjects with stable ankles.

The use of an ankle brace or taping, or both, is recommended as they both give support against ankle inversion when the evertor muscles are relaxed and increase the maximal resistance to inversion with evertor muscles activated. They do seem to be able to enhance proprioceptive awareness, and to decrease the frequency of inversion injuries and decrease the severity of the injuries in groups with functionally unstable ankles.

\section{The role of shoes}

Biomechanical studies support the use of high top shoes for ankle sprain prevention because they limit extreme range of motion, provide additional proprioceptive input, and decrease external stress on joints. ${ }^{129}$ Clinical trials, however, have not shown that the effect of this biomechanically improved stability translates into a lower rate of ankle sprains in high top shoes. Further studies are needed.

\section{Supportive treatment modalities}

Passive physical therapy modalities are often recommended to promote healing in the early rehabilitation phase. The most commonly used are ultrasound, temperature contrast baths, short waves, and various current treatments including dynamic or interference current therapy, or electrogalvanic stimulations. Of these different types of passive physical therapy, only cryotherapy has been proved to be effective. ${ }^{130}$

Non-steroidal anti-inflammatory drugs have been studied in prospective randomised double blind trials, and found to be more effective than placebo for ankle tenderness, swelling, and pain, though the difference was not striking and seemed to disappear during an extended follow up. ${ }^{3130}$

In subjects with chronic post-injury swelling, moist heat packs, warm whirlpool baths, contrast baths, electrogalvanic stimulation, and intermittent pneumatic compression have been tried. ${ }^{4}$ Prospective randomised studies have shown that only the last alternative has an independent ability to reduce the amount of swelling. ${ }^{131} 132$

Table 1 Classification of operative treatments for chronic ankle ligament injury

$$
\begin{aligned}
& \text { Non-anatomical reconstruction } \\
& \hline \text { Non-anatomical reconstruction } \\
& \text { Endogenous } \\
& \text { Peroneal tendon } \\
& \text { Watson-Jones } \\
& \text { Evans } \\
& \text { Chrisman-Snook } \\
& \text { Other } \\
& \text { Plantaris } \\
& \text { Partial Achilles tendon } \\
& \text { Free autogenous graft } \\
& \text { Exogenous } \\
& \text { Carbon fibre } \\
& \text { Bovine xenograft } \\
& \text { Anatomical repair } \\
& \text { Direct suture } \\
& \text { Imbrication and repair to bone } \\
& \text { Local tissue augmentation }
\end{aligned}
$$



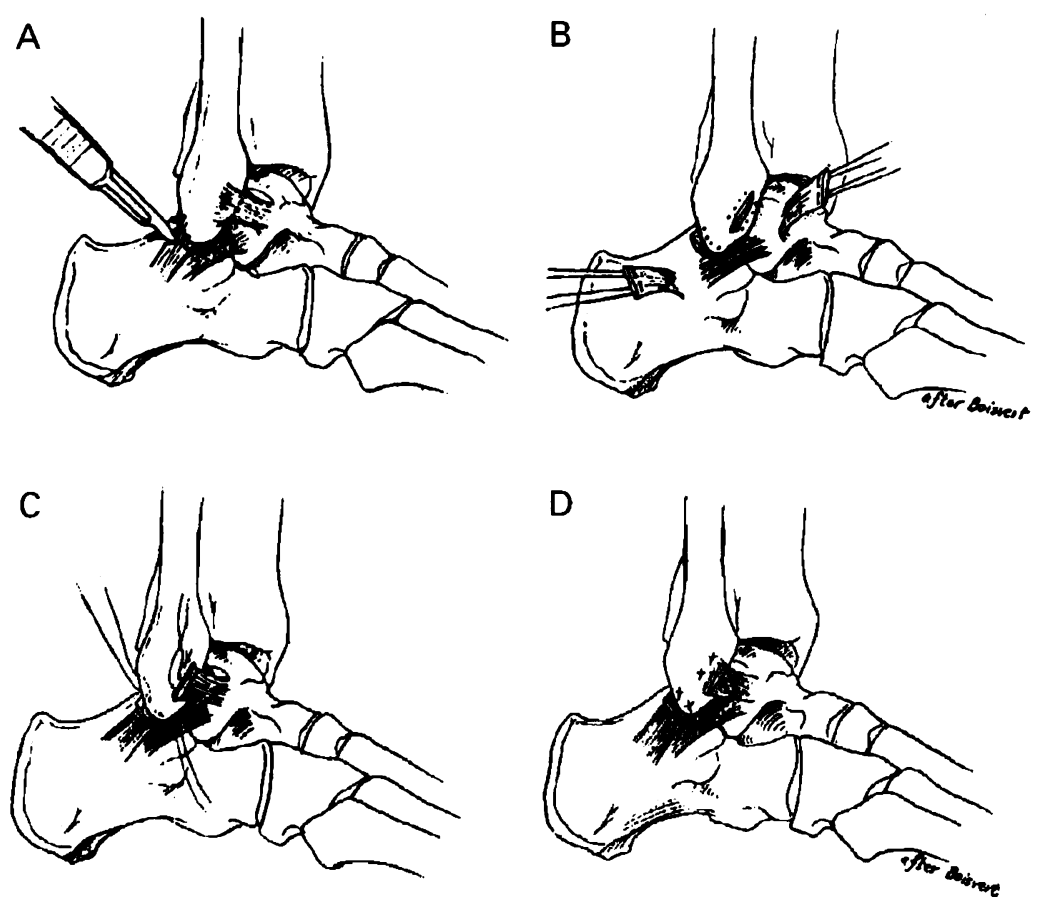

Figure 4 Anatomical reconstruction of chronic ankle ligament instability. (A) Elongated ligaments are divided 3 to $5 \mathrm{~mm}$ from insertion of the fibula. (B) Bone surace of the distal end of the fibula is roughened to form a trough to promote ligament healing. Holes are drilled through the distal fibula. (C) Mattress sutures are used to fix the distal stump of the ligaments and the capsule to the fibula. The sutures are tightened while the foot is held in dorsiflexion and eversion. (D) The proimal ends of the ligaments are imbricated over the distal portion. good. Thus Karlsson et $a l^{33}$ found that the Evans static tenodesis was satisfactory in fewer than $50 \%$ of cases after a mean follow up period of 14 years.

Anatomical reconstructions, in which the tissues of the damaged ligaments are used, have become increasingly popular as they permit reconstruction without sacrificing any normal tissue. ${ }^{3093134}$ Broström in $1966^{30}$ reported that direct suture repair of chronic ankle ligament injuries was possible even many years after the initial injuries and that the ends of the ligament could be found. Others reported that the elongated ligaments had healed encased in a fibrous scar tissue. Several authors have reported successful imbrication or shortening and replantation of the ligaments to obtain a more anatomical reconstruction. We have obtained good results with a modified Broström technique (Peterson procedure) that includes shortening of the ligament, repair through bony tunnels, and imbrication with local tissue ${ }^{93}{ }^{134}$ (fig 4). This anatomical technique repairs both the ATFL and CFL. The non-anatomical reconstructions, except for the Chrisman-Snook modification of the Elmslie procedure, repair only the ATFL. Repair of the CFL is important, because insufficiency of this ligament may be a factor in the development of subtalar instability. The postoperative treatment after an anatomical reconstruction is a splint for eight days to secure wound healing and, thereafter, a removable walking boot for five weeks. The patient starts with dorsiflexion and plantar flexion exercises after eight days or as early as possible out of the boot two to three times a day. Return to sport is usually possible in three months.

Anatomical repair of both the ATFL and the CFL through bony tunnels produces good long term results and is recommended as the initial procedure in most cases. If anatomical repair fails, a tenodesis procedure, such as the Chrisman-Snook reconstruction, is a good alternative. A nonanatomical reconstruction is also indicated in patients with moderate arthritis or lax joints.

1 Makhani JS. Diagnosis and treatment of acute rupture of the various components of the lateral ligaments of the the various components of the la
ankle. Am f Orthop 1962;4:224-30.

2 McCulloch PB, Holden P, Robson DJ, et al. The value of McCulloch PB, Holden $\mathrm{P}$, Robson DJ, et al. The value of
mobilisation and nonsteroidal anti-inflammatory analgesia mobilisation and nonsteroidal anti-inflammatory analgesia
in the management of inversion injuries of the ankle. $B r f$ in the management of inversin Pract 1985;39:69-72.

3 Viljakka T, Rokkanen P. The treatment of ankle sprain by bandaging and antiphlogistic drugs. Ann Chir Gynaecol 1983;72:66-70.

4 Balduini FC, Vegso JJ, Torg JS, et al. Management and rehabilitation of ligamentous injuries to the ankle. Sports Med 1987;4:364-80.

5 Brand RL, Black HM, Cox JS. The natural history of inadequately treated ankle sprain. Am $\mathcal{F}$ Sports Med 1977;5: $248-9$.

6 Fiore RD, Leard JS. A functional approach in the rehabilitation of the ankle and rear foot. Athletic Training 1980;15: 231-5.

7 Garrick JG. The frequency of injury, mechanism of injury and epidemiology of ankle sprains. Am $\mathcal{F}$ Sports Med 1977; 5:241-2.

8 Garrick JG, Requa RK. The epidemiology of foot and ankle injuries in sports. Clin Sports Med 1988;7:29-36.

9 Glick JM, Gordon RB, Nashimoto D. The prevention and treatment of ankle injuries. Am F Sports Med 1976;4:13641 .

10 Hardaker WT, Margello S, Goldner JL. Foot and ankle injuries in theatrical dancers. Foot Ankle 1985;6:59-69. 
11 Lassiter TE Jr, Malone TR, Garrett WE Jr. Injury to the lateral ligaments of the ankle (review). Orthop Clin North Am 1989;20:629-40.

12 McConkey JP. Ankle sprains, consequences and mimics. Medicine and Sports Science 1987;23:39-55.

13 Broström L. Sprained ankles III: Clinical observations in recent ligament ruptures. Acta Chir Scand 1965;130:5609.

14 Ekstrand J, Tropp H. The incidence of ankle sprains in soccer. Foot Ankle 1990;11:41-4.

15 Van Dijk CN. On diagnostic strategies in patients with severe ankle sprain. Amsterdam, Holland: University of Amsterdam, 1994 .

16 Broström L. Sprained ankles I: anatomic lesions in recent sprains. Acta Chir Scand 1964;128:483-95.

17 Rasmussen O. Stability of the ankle joint. Analysis of the function and traumatology of the ankle ligaments. Acta Orthop Scand Suppl 1985;211:1-75.

18 Renstrom P, Wertz M, Incavo S, et al. Strain in the lateral ligaments of the ankle. Foot Ankle 1988;9:59-63.

19 Colville MR, Marder RA, Boyle JJ, et al. Strain measurement in lateral ankle ligaments. $\mathrm{Am} \mathcal{F}$ Sports Med 1990;18: 196-200.

20 Kjaersgaard-Andersen P, Wethelund JO, Helmig P, et al. The stabilizing effect of the ligamentous structures in the sinus and canalis tarsi on movements in the hindfoot. An experimental study. Am $\mathcal{f}$ Sports Med 1988;16:512-6.

21 Cass JR, Morrey BF, Chao KY. Three-dimensional kinematics of ankle instability following serial sectioning of lateral collateral ligaments. Foot Ankle 1984;5:142-9.

22 Cawley PW, France EP. Biomechanics of the lateral ligaments of the ankle: an evaluation of the effects of axial load and single plane motions on ligament strain patterns. Foot Ankle 1991;12:92-9.

23 Dias LS. The lateral ankle sprain: an experimental study. $f$ Trauma 1979;19:266-9.

24 Ozeki S, Yasuda K, Kaneda K. Simultaneous measurement of strain changes and determination of zero strain in the collateral ligaments of the human ankle. 36th Annual Meeting, Orthopaedic Research Society, 1990.

25 Shybut GT, Hayes WC, White AA. Normal patterns of ligament loading among the lateral collateral ankle ligaments. 29th ment loading among the lateral collateral ankle ligaments. 29

26 Stormont DM, Morrey BF, An KN, et al. Stability of the loaded ankle. Relation between articular restraint and primary and secondary static restraints. Am $\mathcal{f}$ Sports Med $1985 ; 13: 295-300$

27 Rasmussen O, Kromann-Andersen C, Boe S. Deltoid ligament. Functional analysis of the medial collateral ligamentous apparatus of the ankle joint. Acta Orthop Scand 1983; $54: 36-44$

28 Smith RW, Reischl SF. Treatment of ankle sprains in young athletes. Am $\mathcal{F}$ Sports Med 1986;14:465-71.

29 Brand RL, Collins MD. Operative management of ligamentous injuries to the ankle. Clin Sports Med 1982;1: 117-30.

30 Broström L. Sprained ankles V - treatment and prognosis in recent ligament ruptures. Acta Chir Scand 1966;135: 537-50.

31 Glasgow M, Jackson A, Jamieson AM. Instability of the ankle after injury to the lateral ligament. $\mathcal{f}$ Bone foint Surg [Br] 1980;62: 196-200.

32 Kjaersgaard-Andersen P, Frich LH, Madsen F, et al. Instability of the hindfoot after lesion of the lateral ankle ligaments: investigations of the anterior drawer and adduction maneuvers in autopsy specimens. Clin Orthop 1991;266:170-9.

33 Leonard $\mathrm{MH}$. Injuries of the lateral ligaments of the ankle. A clinical and experimental study. F Bone foint Surg [Am] 1949;31:373-7.

34 Lindstrand A. New aspects in the diagnosis of lateral ankle sprains. Orthop Clin North Am 1976;7:247-9.

35 Kannus P, Renström P. Current concepts review: treatment for acute tears of the lateral ligaments of the ankle. $\mathcal{f}$ Bone foint Surg [Am] 1991;73:305-12.

36 Gerner-Smidt M. Ankle fractures in children. Copenhagen, Denmark: University of Copenhagen, 1963

37 Hølmer P, Søndergaard L, Konradsen L, et al. Epidemiology of sprains in the lateral ankle and foot. Foot Ankle 1994;15:72-4.

38 Meyer JM, Garcia J, Hoffmeyer P, et al. The subtalar sprain. A roentgenographic study. Clin Orthop 1988;226: 169-73.

39 Taillard W, Meyer JM, Garcia J, et al. The sinus tarsi syndrome. Int Orthop 1981;5:117-30.

40 Taga I, Shino K, Inoue M, et al. Articular cartilage lesions in ankles with lateral ligament injury. Am 7 Sports $\mathrm{Med}$ 1993;21:120-6.

41 Grana WA. Chronic pain persisting after ankle sprain. fournal of Musculoskeletal Medicine 1990;7:35-49.

42 Sammarco GJ. Peroneal tendon injuries. Orthop Clin North Am 1994;25:109-22.

43 Hyslop GH. Injuries to the deep and the superficial peroneal nerves complicating ankle sprain. Am f Surg 1941;51: 436-8.

44 Stoff MD, Greene AF. Common nerve palsy following inversion ankle injury: a report of two cases. Physical Therapy 1982;62:1463-4.

45 Nitz AJ, Dobuer JJ, Kersey D. Nerve injury and grades II and III ankle sprains. Am $\mathcal{F}$ Sports Med 1985;13:177-82.

46 Kleinrensink GJ, Stoeckart R, Meulstee J, et al. Lowered motor conduction velocity of the peroneal nerve after inversion trauma. Med Sci Sports Exer 1994;26:877-83.
47 Norfray JF, Groves HC, Rogers LF, et al. Common calcaneal avulsion fracture. Am $\mathcal{F}$ Roentgenol 1980;134:119-23. 48 Heckman JD, McLean MR. Fractures of the lateral process of the talus. Clin Orthop 1985;199:108-13.

49 Noble J, Royle SG. Fracture of the lateral process of the talus: computed tomographic scan diagnosis. $\operatorname{Br} \mathcal{F}$ Sports Med 1992;26:245-6.

50 Lindenfeld TN. The differentiation and treatment of ankle sprains. Orthopedics 1988;11:203-6.

51 Stepanuk $M$. Arthrography of the ankle joint in the diagnosis of acute ankle sprains. Fournal of the American Orthopedic Association 1977;76:52936.

52 Cass JR, Morrey BF. Ankle instability: current concepts, diagnosis, and treatment. Mayo Clin Proc 1984;59:165-70. 3 Van der Ent FWC. Lateral ankle ligament injury. Rotterdam: Elinkwijk, Utrecht, 1984.

54 Nilsson S. Sprains of the lateral ankle ligaments. An epidemiological and clinical study with special reference to different forms of conservative treatment. Part I. fournal of Oslo City Hospital 1982;32:3-29.

55 Prins JG. Diagnosis and treatment of injury to the lateral ligament of the ankle. A comparative clinical study. Acta Chir Scand 1978; Suppl. 486

56 Stiell IG, McKnight RD, Greenberg GH, et al. Interobserver agreement in the examination of acute ankle injury patients. Am f Emerg Med 1992;10:14-17.

57 van Dijk CN, Lim LSL, Bossuyt PMM, et al. Physical examination is sufficient for the diagnosis of sprained ankles. F Bone Foint Surg [Br] 1996;78:958-62.

58 Stiell IG, McKnight RD, Greenberg GH, et al. Implementation of the Ottawa ankle rules [see comments]. $\Im A M A$ 1994;271:827-32.

59 Jackson DW, Ashley RL, Powell JW. Ankle sprains in young athletes. Relation of severity and disability. Clin Orthop 1974;101:201-15.

60 Clark BL, Derby AC, Power GRI. Injuries of the lateral ligament of the ankle. Conservative vs. operative repair. Can $\mathcal{F}$ Surg 1965;8:358-63.

61 Evans GA, Hardcastle P, Frenyo AD. Acute rupture of the lateral ligament of the ankle. To suture or not to suture? $f$ Bone foint Surg [Br] 1984;66:209-12.

62 Freeman MAR. Treatment of ruptures of the lateral ligament of the ankle. $\mathcal{F}$ Bone foint Surg [Br] 1965;47:661-

63 Grønmark T, Johnsen O, Kogstad O. Rupture of the lateral ligament of the ankle: a controlled clinical trial. Injury 1980;11:215-8.

64 Klein J, Schreckenberger C, Roddecker K. Operative or conservative treatment of recent rupture of the fibular ligament in the ankle. A randomized clinical trial. Unfallchirurgie 1988,91:154-60.

65 Korkala O, Rusanen M, Jokipii P, et al. A prospective study of the treatment of severe tears of the lateral ligament of the ankle. Int Orthop 1987;11:13-17.

66 Møller-Larsen F, Wethelund JO, Jurik AG, et al. Comparison of three different treatments for ruptured lateral ankle son of three different treatments for ruptured
ligaments. Acta Orthop Scand 1988;59:564-6.

67 Niedermann B, Andersen A, Andersen SB, et al. Rupture of the lateral ligaments of the ankle: operation or plaster cast? A propective study. Acta Orthop Scand 1981;52:57987.

68 Sommer HM, Arza D. Functional treatment of recent ruptures of the fibular ligament of the ankle. Int Orthop 1989; 13:157-60.

69 Van Moppes FI, Van den Hoogenband CR. Diagnostic and therapeutic aspects of inversion trauma of the ankle joint. Amsterdam, Holland: Free University, 1982

70 Freeman MA. Instability of the foot after injuries to the lateral ligament of the ankle. F Bone foint Surg $[\mathrm{Br}]$ 1965; 47:669-77.

71 Korkala O, Lauttamus L, Tanskanen P. Lateral ligament injuries of the ankle. Results of primary surgical treatment. Anjuries of the ankle. Results of primar

72 Konradsen L, Hølmer P, Søndergaard L. Early mobilizing treatment for grade III ankle ligament injuries. Foot Ankle 1991;12:69-73.

73 Eiff MP, Smith AT, Smith GE. Early mobilization versus immobilization in the treatment of lateral ankle sprains. Am $\mathcal{F}$ Sports Med 1994;22:83-8.

74 Kaikkonen A, Kannus P, Järvinen M. A performance test protocol and scoring scale for the evaluation of ankle injuries. Am $\mathcal{f}$ Sports Med 1994,22:462-9.

75 Schrier I. Treatment of lateral collateral ligament sprains of the ankle: a critical appraisal of the literature. Clin $\mathcal{F}$ Sport Med 1995;5:187-95.

76 Sommer HM, Schreiber T. Early functional conservative therapy of a fresh fibular rupture of the capsular ligament from a socioeconomic point of view. Sportverletz Sportschaden 1993;7:40-6.

77 Leanderson J, Wredmark T. Treatment of acute ankle sprain. Acta Orthop Scand 1995;66:529-31.

78 Leach RE, Schepsis AA. Acute injury to ligaments of the ankle. In: Evarts CM, ed. Surgery of the musculoskeletal system. Vol 4. New York: Churchill Livingstone, 1990: 3887913.

79 Burry HC. Soft tissue injury in sport. Exerc Sport Sci Rev 1975;3:275-301.

80 Järvinen $M$, Letho $M$. The effect of early mobilization and immobilization on the healing process following muscle injuries. Sports Med 1993;15:78-89.

81 Järvinen M. Healing of a crush injury in rat striated muscle with special reference to treatment of early mobilization and immobilization. Turku, Finland: University of Turku, 1976 . 
82 Letho M. Collagen and fibronectin in healing skeletal muscle injury: an experimental study in rats under variable conditions of physical exercise. Turku, Finland: University of Turku, 1983.

83 Montgomery JB, Steadman JR. Rehabilitation of the injured knee. Clin Sports Med 1985;4:333-43.

84 Akeson WH, Amiel D, Woo SL-Y. Immobility effects on synovial joints: the pathomechanics of joint contracture. Biorheology 1980;17:95-100.

85 Alves J, Alday R, Ketcham D, Lentell G. A comparison of the passive support provided by various ankle braces. $f$ Orthop Sports Phys Ther 1992;15:10-18.

86 Jozsa L, Järvinen $M$, Kannus $P$, et al. Fine structural changes in the articular cartilage of the rat's knee following short-term immobilisation in various positions: a scanning short-term immobilisation in various positions: a scanning

87 Jozsa L, Thoring J, Järvinen M, et al. Quantitative Jozsa L, Thoring J, Järvinen $\mathrm{M}$, et al. Quantitative alterations in intramuscular connective tissue following immobilization: an experimental study
cles. Exp Mol Pathol 1988;49:267-78.

88 Jozsa L, Reffy A, Järvinen M, et al. Cortical and trabecular osteopenia after immobilization. A quantitative histological study of the rat knee. Int Orthop 1988;12:169-72.

89 Noyes FR. Functional properties of knee ligaments and alterations induced by immobilization. Clin Orthop 1977 123:210-42.

90 Ogata K, Whiteside LA, Andersen DA. The intra-articular effect of various postoperative managements following knee ligament repair: an experimental study in dogs. Clin Orthop 1980;150:271-6.

91 Woo SL, Inoue M, McGurk-Burleson E, et al. Treatment of the medial collateral ligament injury. II: Structure and function of canine knees in response to differing treatment function of canine knees in response to differ

92 Renström P, Kannus P. Injuries of the foot and ankle. In DeLee JC, Drez DJ, eds. Orthopaedic sports medicine: principles and practice. Vol 2. Philadelphia: Saunders, 1994: 1705-67.

93 Karlsson J, Bergsten T, Lansinger O, et al. Reconstruction of the lateral ligaments of the ankle for chronic latera instability. $\mathcal{F}$ Bone foint Surg $[\mathrm{Am}]$ 1988;70:581-8.

94 Mann G, Eliashuvo O, Perry C. Recurrent ankle sprain literature review. Israel fournal of Sports Medicine 1994;4 104-13.

95 Tropp H. Functional instability of the ankle joint. Linkoping, Sweden: Linkoping University, 1985.

96 Freeman MAR, Dean MRE, Hanham IWF. The etiology and prevention of functional instability of the foot. $\mathcal{F}$ Bone foint Surg $[B r] 1965 ; 47: 678-85$.

97 Harper MC. The lateral ligamentous support of the subtalar joint (review). Foot Ankle 1991;11:354-8.

98 Konradsen L, Ravn JB. Prolonged peroneal reaction time in ankle instability. Int $\mathcal{f}$ Sports Med 1991;12:290-2.

99 Karlsson J, Lansinger O. Lateral instability of the ankle joint. Clin Orthop 1992;276:253-61.

100 Löefvenberg R, Kärrholm J, Sundelin G. Prolonged reaction time in patients with chronic lateral instability of the ankle. $A m \mathcal{F}$ Sports Med 1995;23:414-7.

101 Isakov E, Mizrahi J, Solzi P, et al. Response of the peronea muscles to sudden inversion of the ankle during standin International fournal of Sports Biomechanics 1986;2:100-9.

102 Brunt D, Andersen JC, Huntsman B, et al. Postural responses to lateral perturbation in healthy subjects and ankle sprain patients. Med Sci Sports Exerc 1992;24:171-6.

103 Johnson MB, Johnson CL. Electromyographic response of peroneal muscles in surgical and nonsurgical injured ankles during sudden inversion. Fournal of Sports Physical Therapy 1993;18:497-501.

104 Glencross D, Thornton E. Position sense following joint injury. I Sports Med Phys Fitness 1981;21:23-7.

105 Garn SN, Newton RA. Kinesthetic awareness in subjects with multiple ankle sprains. Phys Ther 1988;68:1667-71.

106 Jerosch J, Hoffstetter I, Bork $\mathrm{H}$, et al. The influence of orthoses on the proprioception of the ankle joint. Knee Surg Sports Traumatol Arthrosc 1995;3:39-46.

107 Gross MT. Effects of recurrent lateral ankle sprains on active and passive judgement of joint position. Phys Ther 1987;67: 1505-9.

108 Leanderson J, Eriksson E, Nilsson C, et al. Proprioception in classical ballet dancers: a prospective study of the influence of an ankle sprain on proprioception in the ankle joint. Am $\mathcal{F}$ Sports Med 1996;24:370-4.
109 Chrisman OD, Snook GA. Reconstruction of lateral ligament tears of the ankle. I Bone foint Surg [Am] 1969;51:904-12.

110 Clanton TO. Instability of the subtalar joint (review). Orthop Clin North Am 1989;2:583-92.

111 Karlsson J, Renström P. Subtalar ankle instability. Scand $\mathcal{f}$ Sports Med (in press)

112 Grimby G. Clinical aspects of strength and power training. Blackwell Scientific, 1992: 338-56.

113 Karlsson J, Lansinger O. Chronic lateral instability of the ankle in athletes. Sports Med 1993;16:355-65.

114 Ashton-Miller JA, Ottaviani RA, Hutchinson C, et al. What best protects the inverted weightbearing ankle against furbest protects the inverted weightbearing ankle again
ther inversion. Am $₹$ Sports Med 1996;24:800-9.

114a Garrick JG, Requa RK. The role of external support in prevention of ankle sprains. Med Sci Sports 1973;5:200-3.

115 Lindenberger U, Reese D, Andreasson G, et al. The effect of prophylactic taping of ankles. Gothenburg, Sweden: Chalmers Technical University, 1985. 116 Fumich RM, Ellison AE, Guerin GJ et al. The measured
effect of taping on combined foot and ankle motion before and after exercise. Am $\mathcal{F}$ Sports Med 1981,9:165-70.

117 Rarick GL, Bigley G, Karst R. The measurable support of the ankle joint by conventional methods of taping. 7 Bone foint Surg [Am] 1962;44:1183-90.

118 Larsen E. Taping the ankle for chronic instability. Acta Orthop Scand 1984;55:551-3.

119 Myburgh KH, Vaughan CL, Isaacs SK. The effect of ankle guards and taping on joint motion before, during, an guards and taping on joint motion before, during, a
after a squash match. Am $\mathcal{f}$ Sports Med 1984;12:441-6.

120 Karlsson J, Bergsten T, Lansinger O, et al. Surgica treatment of chronic lateral instability of the ankle joint. A new procedure (review). Am $\mathcal{F}$ Sports Med 1989;17:26873; discussion 273-4

121 Shapiro MS, Kabo JM, Mitchell PW, et al. Ankle sprain prophylaxis: an analysis of the stabilizing effects of brace and tape. $A m \mathcal{F}$ Sports Med 1994;22:78-82.

122 Rovere GD, Clarke TJ, Yates CS. Retrospective comparison of taping and ankle stabilizers in preventing ankle injuries. Am 7 Sports Med 1988;16:228-33.

123 Sitler M, Ryan J, Wheeler B, et al. The efficacy of a semirigid ankle stabilizer to reduce acute ankle injuries in basrigid ankle stabilizer to reduce acute ankle injuries in bas-
ketball. A randomized clinical study at West Point. $\mathrm{Am}$ ketball. A randomized clinical
Sport 1994;22:454-61.

124 Nishikawa T, Grabiner MD. Ankle braces influence the reflex amplitude of muscle in response to stretch. 42nd Annual amplitude of muscle in response to stretch. 42
Meeting, Orthopaedic Research Society, 1996.

125 Greene TA, Wright CR. A comparative support evaluation of three orthoses before, during and after exercise. $\mathcal{J}$ Orthop Sports Phys Ther 1990;11:453-66.

126 Burks RT, Marcus R, Bean BG, Barker HB. Analysis of athletic performance with prophylactic ankle devices. $A m$ Sports Med 1991;19:104-6.

127 Coffman JL, Mize NL. A comparison of ankle taping and the Aircast sport-stirrup on athletic performance. Athletic Training 1989;24:123-8.

128 Gross MT, Everts JR, Roberson SE. Effect of DonJoy ankle ligament protector and Aircast sport-stirrup orthoses on ligament protector and Aircast sport-stirrup orthoses on
functional performance. $f$ Orthop Sports Phys Ther functional perfor

129 Barrett J, Bilisko T. The role of shoes in the prevention of ankle sprains. Sports Med 1995;20:227-80.

130 Cote DJ, Prentice WE Jr, Hooker DN, et al. Comparison of three treatment procedures for minimizing ankle sprain swelling. Phys Ther 1988;68:1072-6.

131 Airaksinen O, Kolari PJ, Herve R, et al. Treatment of posttraumatic oedema in lower legs using intermitten pneumatic compression. Scand F Rehabil Med 1988;20:258.

132 Airaksinen $\mathrm{O}$. Changes in posttraumatic ankle joint mobility, pain, and edema following intermittent pneumatic

133 Tohyama H, Beynnon BD, Renstrom P, Pope MH. Laxity and stiffness of normal and reconstructed ankles using Chrisman-Snook procedure. 61 st Annual Meeting, American Academy of Orthopaedic Surgeons.

134 Althoff B, Peterson L, Renstrom P. A simple reconstructive procedure of chronic ligament injuries of the ankle. Lakertidningen 1981;78:2857-61. 